\title{
INVESTIGAÇÃO SOBRE O USO DE TEXTOS DE DIVULGAÇÃO CIENTÍFICA COM ESTUDANTES DO ENSINO MÉDIO DO CEFET/RJ
}

\author{
RESEARCH INTO THE USE \\ OF TEXTS OF SCIENTIFIC \\ DISSEMINNATION WITH HIGH \\ SCHOOL STUDENTS OF CEFET/RJ
}

\section{RESUMO}

O projeto "Educação Ambiental e Ciência: o papel da mídia na difusão de conhecimentos ambientais" vem sendo desenvolvido desde 2013 no Centro Federal de Educação Tecnológica Celso Suckow da Fonseca, no Rio de Janeiro. O objetivo deste projeto de extensão é investigar como o texto de divulgação científica, ou seja, a mídia impressa contribui para a reflexão crítica das questões ambientais por alunos do ensino médio. Este artigo, portanto, apresenta os resultados de uma atividade pedagógica baseada na leitura e discussão de uma reportagem do Jornal O Globo sobre poluição atmosférica com três turmas do $3^{\circ}$ ano do ensino médio. Foram aplicados dois questionários, um pré e um pós-diagnóstico para analisar como os alunos articulavam os conceitos relacionados ao tema. A partir disso, pode-se concluir que o uso dos textos de divulgação científica, adequadamente organizado, associado à mediação do professor, possibilitou que os alunos fossem além da memorização de termos e conceitos científicos. Desta forma, esse material contribuiu para uma aprendizagem significativa de questões relacionadas ao meio ambiente.

Palavras-chave: Divulgação Científica. Meio ambiente. Educação Ambiental.

\section{ABSTRACT}

The project "Environmental Education and Science: the role of the media in disseminating environmental knowledge" has been carried out since 2013 at Centro Federal de Educação Tecnológica Celso Suckow da Fonseca in Rio de Janeiro. It aims to investigate how texts of scientific dissemination, that is print media, contribute to the critical reflection of high school students about environmental issues. Thus, it presents the results of an education activity based on reading and discussing a report of the newspaper O Globo on air pollution with the third year of high school students. Before and after the activity, students were asked to fill in questionnaires in order to be possible an analysis of how they articulate the concepts related to the topic. It was possible to conclude that the use of scientific texts, properly organized and with the

1 Professor do Centro Federal de Educação Tecnológica Celso Suckow da Fonseca (CEFET/RJ), Brasil. Doutorado em Zoologia pela Universidade Federal do Rio de Janeiro (UFRJ), Brasil. E-mail: rochamarcelo36@yahoo.com.br

2 Graduado em Gestão Ambiental pelo Centro Federal de Educação Tecnológica Celso Suckow da Fonseca (CEFET), Brasil. E-mail: landimj@hotmail.com 
teacher mediation, allow students to go beyond memorization of scientific terms and concepts. In sum, the activities contributed to a significant learning experience about environmental issues.

Keywords: Scientific Dissemination. Environment. Environmental Education.

\section{Introduçáo}

O "Educação Ambiental e Ciência: o papel da mídia na difusão de conhecimentos ambientais" é um projeto de extensão que vem sendo desenvolvido desde 2013 no Centro Federal de Educaçáo Tecnológica Celso Suckow da Fonseca, no campus Maracană, no Rio de Janeiro. Este projeto tem como objetivos elaborar e oferecer oficinas de Educação Ambiental, a partir do uso da mídia impressa, como forma de problematizar e discutir questóes relacionadas ao meio ambiente com alunos do Ensino Médio. Além disso, através das atividades oferecidas, oportuniza-se que os alunos tenham contato com outros tipos de leitura, que vão além do livro didático. Sendo assim, o projeto destaca a importância da leitura de textos de divulgação científica em contextos escolares na formação de sujeitos leitores críticos.

Para alcançar os objetivos, são realizadas oficinas de leitura de artigos publicados em jornais e revistas com alunos do Ensino Médio. Essas oficinas ocorrem como atividades extraclasses, por isso, em horário alternativo à grade curricular da escola. A escolha dos textos utilizados se dá a partir dos seguintes critérios: linguagem compatível com a idade dos alunos; disponibilidade de conteúdos e informaçóes sobre temáticas ambientais; texto acompanhado de figuras ilustrativas, com o objetivo de estimular os alunos; texto desprovido de sensacionalismo, que aborde fatos e acrescente informaçóes para o processo de ensino-aprendizado dos alunos.

O projeto supracitado surge em um contexto em que cada vez mais se faz necessário repensar a forma como o homem tem interagido com o meio ambiente, tendo em vista os impactos de suas açóes sobre ele mesmo e aos demais seres vivos. À medida que os resultados da degradação ambiental se apresentam de forma mais expressiva, aumentam as discussóes no âmbito nacional e internacional sobre o problema, e a divulgação científica é usada como uma das principais ferramentas de veiculação desses assuntos para o público (ROCHA; NICODEMO, 2013).

Dentro do "Educação Ambiental e Ciência: o papel da mídia na difusão de conhecimentos ambientais", são desenvolvidas atividades de ensino, pesquisa e extensão. Como ação de extensão, destacase a Educação Ambiental (EA), que atua como forma de sensibilizar os indivíduos para o enfrentamento da problemática ambiental, que envolve aspectos sociais, econômicos e ecológicos.

Pode-se considerar atividades voltadas a EA de extrema importância, levando em consideraçáo que funcionam como ferramentas para a sensibilização dos cidadãos sobre o seu papel na sociedade. A Educaçáa Ambiental deve favorecer os processos que permitam que os indivíduos e os grupos sociais ampliem a sua percepção e internalizem, conscientemente, a necessidade de mudanças.

Sendo assim, o objetivo deste trabalho é descrever uma atividade de EA desenvolvida como parte do projeto de extensão a partir de oficinas de leitura e aprofundamento de questóes ambientais com alunos do $3^{\circ}$ ano do Ensino Médio.

\section{Revisão de Literatura}

Atividades de divulgaçáo da ciência e da tecnologia têm um importante papel social, uma vez que podem servir como instrumento na construção de uma consciência científica de públicos não especializados. Nessas atividades, são utilizados textos informativos voltados para a traduçáo de uma 
linguagem técnica para uma linguagem leiga, que, posteriormente, são transmitidos ao público geral.

Levando-se em conta a versatilidade do conteúdo presente nos textos de divulgaçáo científica, que tornam públicas discussóes de vários assuntos, em diversas áreas do conhecimento, verifica-se a possibilidade de incorporá-los no cenário escolar e usá-los como material auxiliar para abranger os mais diversos contextos sociais, sobretudo as discussões ambientais.

Segundo Rocha (2010), a chegada da economia globalizada e a forte influência dos meios de comunicação e dos recursos tecnológicos, aliados à mudança de paradigma da ciência, não comportam um ensino nas escolas que se caracteriza por uma prática pedagógica conservadora, repetitiva e acrítica. Pensando nisso, torna-se válida a aplicaçáo de elementos que podem contribuir para o desenvolvimento de atividades que estimulem a criatividade e o senso crítico nos alunos. Em virtude disso, textos divulgados pelos variados meio de comunicação podem ser utilizados como um recurso útil nesse processo.

A leitura e a inserção de novos conceitos em sala de aula são fundamentais para estimular o interesse do aluno por assuntos discutidos na atualidade. De acordo com Nascimento (2005), o uso de textos de divulgação científica nas aulas de ciências é uma tendência que promove a inserção de temas atuais ao ensino formal, além de desempenhar diferentes funções, tais como: elementos motivadores ou estruturadores da aula; desencadeadores de debate; contextos para a aquisição de novas práticas de leitura; interlocutores com outras áreas do conhecimento; elementos que estabelecem relaçóes com o cotidiano dos estudantes; organizadores de explicaçóes.

Em algumas vezes, os livros didáticos não se comunicam com o leitor, eles simplesmente lançam as informaçóes, com o objetivo de ensinar terminologias e conceitos, por intermédio de um mediador que transmite o conhecimento para o aluno. Os objetivos e modos de avaliação dos livros produzidos para o ensino formal são muito diferentes dos da divulgação científica (DC), segundo Sanchéz Mora (2003, p.99).

[...] o divulgador não deve confundi-los. A palavra "aprendizagem", na divulgação, possui um significado muito mais amplo; o conhecimento é partilhado, e não comunicado. $\mathrm{O}$ bom divulgador dialoga com um leitor inteligente, seja qual for a idade e o grau de formação dele.

Assim, o divulgador ou jornalista científico deve pensar além da coletividade na produção de um texto, mas também no educador, que deve ter entendimento pleno do assunto para passar aos seus alunos, além de estar preparado para responder questionamentos e tirar dúvidas referentes ao tema. Outros autores, como Sánchez Mora, defendem esta ideologia ao dizer que o divulgador não é um cientista especializado em determinado ramo da ciência e, sim, um especialista nas questōes pedagógicas (BUENO, 2010).

Sobre meios de comunicaçáo, alguns certamente são mais restritivos que outros, interferindo em maior ou menor escala nos fins aos quais a DC se presta. Na imprensa, a pauta de meio ambiente está quase sempre submetida aos interesses dos próprios meios de comunicação e até de seus mercadores, além de sofrer com a óbvia concorrência com outras pautas, fato que lhe tolhe tempo e espaço.

Aliás, segundo jornalistas como Christofolleti (2001), há que se considerar também que o conceito de verdade que rege o trabalho na maioria dos meios de comunicação não está em consonância com os fins educativos da divulgaçáo científica. Segundo o autor, a 
"verdade" subjacente às notas e matérias tem sempre um caráter latente de absolutismo, de vigor inconteste, de impossibilidade de erro, que praticamente inviabiliza a noção de meio ambiente que a DC deve pressupor tornar pública.

O público desempenha um papel fundamental na DC, já que é nele que se projetam os objetivos destas atividades. Rigotti (2001) discute a inviabilidade do 'modelo de déficit', que julga o público, antecipadamente, como uma tábula rasa, e sinaliza a necessidade de se ter em conta as circunstâncias particulares da audiência, seus conhecimentos, crenças e atitudes em relação ao tema meio ambiente. Existem demandas distintas e públicos diferenciados, de forma que a DC precisa atuar com estratégias também distintas para tornar possível atendê-las.

A maioria da informação ambiental de que dispóe o cidadão lhe chega por meio dos meios de comunicação. Grande parte dos indivíduos não têm à sua disposição um temário de EA no ensino regular. Esta realidade faz com que instituiçóes e entidades de âmbito ambiental percebam, no exercício jornalístico, uma ferramenta muito interessante para este processo formativo ou educativo.

O papel do jornalista ambiental é identificar as notícias vinculadas a esta especialidade e explicar os diferentes fatores do acontecimento, de forma que o leitor possa entender por que se chegou a essa situação, as tendências e a evolução de um determinado problema ecológico, energético ou eco social.

$\mathrm{Na}$ ótica de Freire (2003), o jornalismo ambiental enfrenta, no Brasil, há muito tempo, inúmeros desafios. Um dos principais está relacionado com o conceito de jornalismo ambiental, que deriva da imagem de meio ambiente que é divulgado, assumindo o meio ambiente como algo distante da realidade que cerca o ser humano, como somente florestas, animais em extinção, calotas polares derretendo, entre outros.

Não há como negar que, na atualidade, dois modos de aprendizagem coexistem e interagem: a escola e os meios de comunicação em massa. Deve-se considerar a educação como um processo formativo da personalidade do indivíduo, ao longo de sua vida, pois cada vez mais se pode aprender fora da escola, e isso acontece em função da imprensa, do cinema, do rádio e da televisão.

Se os meios de comunicação são um ambiente considerável de aprendizagem, os materiais de divulgação científica publicados neles são ferramentas importantes para veiculação dos resultados das pesquisas científicas à sociedade. Segundo Alferes e Agustini (2008), os textos de divulgação científica também podem ter uma função educativa. Desse modo, é possível estimular as pessoas a aprenderem mais, contribuindo para a educação à proporção que se informa ostensivamente o público.

Conforme Massarani (2008), apesar de um aumento do interesse acadêmico na realização de atividades de extensão ligadas à divulgação científica, observa-se ainda, uma situação fragilizada, se levada em conta a ocorrência frequente de aulas centradas na leitura exclusiva de livros didáticos. Diante desse quadro, verifica-se a necessidade de buscar resultados embasados em pesquisas no próprio ambiente escolar para apresentá-los aos docentes, motivando-os a utilizarem textos de divulgação científica em suas aulas.

Matérias de jornais e revistas expóem diariamente informações de inovaçóes que tratam da temática ambiental. Todo esse conteúdo informativo vem de forma e linguagem acessíveis para a compreensão do leitor comum. Seu caráter descritivo tende a servir como auxiliar no aprendizado, podendo também ser empregado como material didático, por apontar exemplos práticos e reais aos estudantes. Atualmente, vários 
autores, como Nascimento (2005) e Rocha (2010), apontam que os textos de divulgaçáo científica são uma ferramenta pedagógica importante para a veiculaçăo de conhecimentos e terminologias científicas em atividades de sala de aula.

Textos de divulgação científica têm sido sugeridos em pesquisas da área de educação em ciências, como capazes de complementar o uso de materiais educativos tradicionais, como os livros didáticos (SILVA; ALMEIDA, 2005; ABREU et al., 2007; QUEIROZ et al., 2012). Essas pesquisas têm se alicerçado na importância da realizaçáo de atividades que, além de auxiliarem e facilitarem o aprendizado de conceitos científicos, contribuam para a formação de hábitos e atitudes, não só no âmbito da escola, mas também fora do ambiente escolar. Os Parâmetros Curriculares Nacionais para o Ensino Médio (PCNEM) apontam para esta importância, quando explicitam que:

Lidar com o arsenal de informaçóes atualmente disponíveis depende de habilidades para obter, sistematizar, produzir e mesmo difundir informaçóes [...]. Isso inclui ser um leitor crítico e atento das notícias científicas divulgadas de diferentes formas: vídeos, programas de televisão, sites da Internet ou notícias de jornais (BRASIL, 1999, p.27).

Isto significa que é de extrema importância, para a formação de leitores, que a busca pela informação não esteja restrita à escola, mas seja, também, abrangente, de modo que esteja presente no cotidiano por intermédio de diversos meios, como livros, jornais, televisão, noticiários e, principalmente, a internet, que é o veiculo de informaçōes mais utilizado da atualidade.

Alguns autores sugerem que essas estratégias didáticas, que apresentam uma variedade de formas de argumentação e pontos de vista, são importantes para a valorização do contato dos alunos com diferentes tipos de textos científicos e podem acarretar no aluno uma série de benefícios, como o desenvolvimento de habilidades de leitura e domínio de conceitos, formas de argumentação científica, elementos de terminologia científica, acesso a uma maior diversidade de informaçóes, introdução de novos conceitos, compartilhamento de informaçóes entre os alunos, entre outros. Isso permite aos alunos que, através do conhecimento adquirido de diversos tipos de textos científicos, desde textos originais de autorias de cientistas até reportagens publicadas em mídia, tenham a possibilidade de se tornar um participante ativo da cultura científica.

Ao adotarem o uso de textos de divulgaçáo científica em uma perspectiva investigativa, verificaram que estratégias desse tipo permitem que os alunos assumam posiçóes e construam juízos de valor, estabeleçam relaçôes, mobilizem seus conhecimentos para solucionar situaçóes-problema e, numa perspectiva mais ampla, transponham esses conhecimentos para a sua vida diária (MENEGAT et al., 2007).

Esse impacto da DC na realidade do aluno tem se tornado tema de uma variedade de trabalhos e pesquisas que buscam entender a experiência do uso de textos de divulgação científica no ensino de diversas disciplinas (FERREIRA; QUEIROZ, 2012). Cada professor apresenta uma maneira peculiar de introdução de conceitos da divulgação científica para alcançar os objetivos almejados, e algumas condiçóes de trabalho foram estabelecidas pelos pesquisadores e professores mediante o uso dos textos de divulgaçáo científica.

Sulaiman (2011), associando a EA com a divulgação científica, aponta que a mídia assume um papel educativo, sobretudo frente à problemática ambiental contemporânea. A autora faz ressalva quanto às estratégias e aos conteúdos abordados sobre o tema. Mesmo 
assim, ela argumenta que a "crise" ambiental, de fato, ganhou notoriedade e relevância social por meio da mídia, que se subdividiu em temas menores: mudança climática, aquecimento global, biodiversidade, ambientalismo, sustentabilidade e cidadania ambiental.

Belmonte (2004) ressalta a necessidade de cobertura de qualidade no que diz respeito às informaçôes ambientais veiculadas nos meios de comunicação. Defende, ainda, o debate público sobre a questão ambiental, e não apenas enfoques superficiais, baseados em sensacionalismo e visóes apocalípticas, inserindo o meio ambiente na vertente do espetáculo, e não da educação.

A mídia tem se tornado responsável por grande parte das informaçóes que os cidadáos possuem sobre as questóes ambientais. Todos os dias, jornais e revistas, entre outros meios de comunicação, trazem notícias que informam e discutem recentes avanços científico-tecnológicos e sua relaçáo com o meio ambiente. Desta forma, percebe-se que a divulgação científica na mídia impressa exerce uma grande influência na formação de opiniáo dos leitores, visto que, através dela, o público toma contato com os problemas ambientais e procura rediscutir questôes sobre a relaçáo homem-ambiente (ROCHA, 2010).

Assim, em termos conceituais, ciente da impossibilidade de concepçóes universais, afirma-se que a divulgação da ciência se refere, sobretudo, ao conjunto de procedimentos transformadores advindos da vinculação ciência-tecnologia e de seus resultados inscritos no meio ambiente, haja vista que o interesse maior da ciência é a emancipação do gênero humano, seja em relaçáo à natureza, seja em relaçáo às suas limitaçóes sociais, culturais e existenciais. Envolve acepçóes distintas e, ao mesmo tempo, próximas, tais como: os métodos específicos (científicos) que propiciam a comprovaçáo dos conhecimentos; os conhecimentos decorrentes da aplicação desses métodos; a conjunçáo de valores culturais que governam essas atividades ditas científicas; e a própria combinação dos elementos ora citados.

No entanto, Souza e Fernandes (2008) apontam que mídia e meio ambiente parecem se encontrar num momento crítico da história: o da crise dos modelos de desenvolvimento, calcados na exploraçáo sem limites dos recursos naturais e no consequente esgotamento destes últimos. É nesse contexto que se consolida o processo de industrialização e a ocupação desordenada do espaço urbano, impulsionada pela expropriaçáo camponesa, como garras afiadas do capital na materialização do círculo vicioso do lucro.

Observa-se, então, que a discussão ambiental permeia várias atividades da sociedade. Desta forma, desenvolvem-se questôes com relação à forma de a mídia impressa contemplar a temática ambiental, como a periodicidade em que isso acontece, quais abordagens sobre a temática ambiental aparecem nas revistas, e, ainda, com que recursos linguísticos esse tema é abordado nas diferentes ferramentas de divulgação. Dado que o veículo midiático influencia diretamente na formaçáo da opiniáo acerca dos temas ambientais, observa-se que, de fato, o assunto meio ambiente está constantemente incluso nos princípios editoriais destes veículos. Assuntos como o aquecimento global, por exemplo, ganham sempre grande repercussão na mídia.

Segundo Bernardes et al. (2009), a cobertura jornalística sobre o aquecimento global, sem dúvida, fez do tema um dos mais populares do universo, até então, restrito aos gabinetes científicos. $\mathrm{O}$ autor também aponta que, com o amadurecimento do 
jornalismo especializado em ciência, pressupóe-se que este esteja mais preparado para cobrir temas polêmicos, complexo e de tantas incertezas, diferentemente da imprensa não especializada, que tende a repetir o discurso origem e, portanto, não promove o debate que o tema demanda.

Gonzáles-Gaudiano e Lorenzetti sinalizam que revistas de divulgação científica também contribuem para a divulgação dos conhecimentos ambientais, visto que:

Os artigos de Educação Ambiental permeiam, com muita frequência, as principais revistas relacionadas ao ensino de ciências e de educação. Com isso, a área de pesquisa ganhou em termos de publicaçóes teóricas mais consistentes, com produção de materiais de mais qualidade que podem influenciar a prática pedagógica. Pelo exposto, depreende-se que a Educação Ambiental no Brasil possui uma trajetória que vem se desenvolvendo gradativamente, mas ainda resta um longo caminho a ser percorrido (GONZÁLES-GAUDIANO; LORENZETTT, 2009, p. 60).

Para que a EA ocorra de forma efetiva, é necessária a implantação de diferentes recursos que atualizem o público das complicaçóes e problemas enfrentados na natureza e da forma como se portar para melhorar ou reverter tal situação. Sendo assim, cabe ressaltar que a divulgação científica pode ser apontada como ferramenta de precisa relevância, uma vez que ela leva informaçóes atualizadas ao público, além de apresentar formas e recomendaçóes de como se portar diante de problemas ambientais e de outras realidades que relacionam homem e natureza.

Muitas pesquisas desenvolvidas atualmente na área de EA apontam alternativas para superar as dificuldades vivenciadas por docentes e estudantes inseridos no cenário educacional brasileiro. Dentre tais estudos, destacam-se os que sugerem o uso de textos de divulgação científica como ferramentas capazes de proporcionar melhorias na qualidade do processo de ensino e aprendizagem (TERRAZZAN, 2000; GOUVÊA, 2002; GOLBDACH et al., 2005; GOMES, 2008). Estudos mostram que tem sido eficaz a utilização desse material em sala de aula, pois permite que o processo aproxime a ciência do aluno através de uma exposição de temas que fazem parte do cotidiano.

\section{Metodologia}

Todo o processo desta pesquisa foi voltado para a elaboração e aplicação de oficinas pedagógicas com textos de divulgação científica, em três turmas de $3^{\circ}$ ano do Ensino Médio do Centro Federal de Educação Tecnológica Celso Suckow da Fonseca, dentro do projeto de extensão.

Para a realizaçáo das atividades, foi selecionada uma reportagem publicada no dia 30 de outubro de 2012, no jornal O Globo, versão impressa (Figura 1). $\mathrm{O}$ assunto principal trata da poluição atmosférica no Brasil e sobre os padrões defasados de análise da qualidade do ar em território nacional, apresentados por um estudo realizado pelo Instituto de Energia e Meio Ambiente (Iema), que comparou os limites brasileiros com os usados no EUA, União Europeia e vários outros países, além das últimas recomendaçôes da Organização Mundial de Saúde (OMS).

A discussão sobre poluição tomou grandes proporçóes, na medida em que se trata de um acontecimento real, que está impactando a sociedade em todo o mundo. Diversos impactos ligados à poluição atmosférica têm sido mostrados e relatados nos principais 
veículos de comunicação, tanto impressa quanto televisiva. Por este motivo, as escolas e os professores têm se preocupado em contextualizar e explicar esta realidade.

A compreensão de um texto escrito, por ser um processo cognitivo, obviamente náo pode ser ensinada e requer o conhecimento prévio do leitor. Para auxiliar o processo de compreensão, é necessário que sejam criadas oportunidades que permitam o desenvolvimento e processamento das informaçóes, através de uma ação interativa que envolve processos textuais e linguísticos, permitindo que o leitor faça a relaçáo das informaçóes disponíveis no texto. Segundo Kleiman (1989), estão envolvidos: o engajamento do conhecimento prévio, o conhecimento textual e a ativação do conhecimento do mundo, para que não fique perdido no fundo da memória.

A atividade proposta baseou-se em um texto de divulgação científica apresentado aos alunos e análise da intensidade do impacto positivo, negativo ou nulo nos alunos. A escolha do texto que norteou a atividade foi fundamental, considerando o públicoalvo. Foram estabelecidos critérios que deveriam ser cumpridos pelo texto para que fosse possível a sua escolha. Dentre os critérios, estão: linguagem compatível com a idade dos alunos; disponibilidade de conteúdos e informaçóes sobre a temática poluição atmosférica; texto acompanhado de figuras ilustrativas, com o objetivo de estimular os alunos; texto desprovido de sensacionalismo, que contivesse fatos e pudesse, realmente, acrescentar informações aos alunos referentes ao tema.

\section{Figura 1: Reportagem extraída do Jornal O Globo} Padrão de qualidade do ar do Brasil está defasado

\section{Estudo comparou limites adotados no país com os de outras naçäes e recomendacão da OMS}

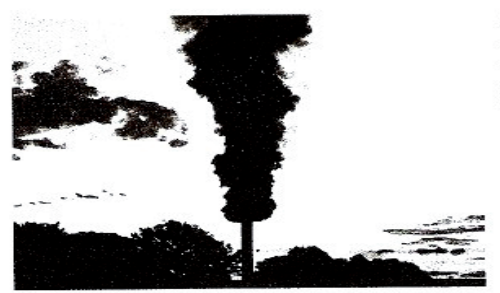

RIO - O padrão de qualidade do ar adotado pelo Brasil está defasado, e no caso de alguns poluentes, segue diretrizes com quase 40 anos de idade, necessitando por isso rediscussão urgente quase 40 anos de idade, necessitando pora a ambiente. A conclusão é de estudo realizado pelo Instituto de Energia e Meio Ambiente (Iema), que comparou os limites brasileiros com os usados por (Iema), que comparou os limites brasileiros com os usados por recomendações da Organização Mundial da Saude (OMS). Segundo o levantamento, com exceção do monoxido de carbono (CO) e da concentração de ozônio (O3) respirável, a regulamentação no país deixa a desejar com relação aos principais poluentes atmosféricos, como material particulado, dióxido de enxofre (SO2) e óxidos de nitrogênio (NOx).

André Luis Ferreira diretor-presidente do Iema, conta que o padrão brasileiro foi estabelecido pelo Conselho Nacional do Meio Ambiente (Conama) em 1990 e permanece o mesmo desde então, enquanto no resto do mundo costuma ser revisto periodicamente. Além disso, Ferreira lembra que os limites adotados tiveram como base os que já eram usados pelos primeiros programas de monitoramento da qualidade do ar no país, criados no Rio e em São Paulo na década de 70, que por sua vez se espelhavam nos que os EUA usavam na época.

- Estamos muito longe das recomendações atuais da OMS - afirma. - Alguns valores na resolução do Conama estão completando quase 40 anos. Não houve revisão, nem se discute o assunto.

Ferrcira aponta como o primeiro grande defeito da resolução do Conama que esta não estabelece um padrão para o chamado MP2.5, o material particulado mais fino, com até 2,5 micrômetros (milésimos de milímetro) de diâmetro, o mais nocivo à saúde por atingir regiōes mais profundas dos pulmões, podendo levar a problemas respiratórios, carđiovasculares e até câncer. A atual legislação do pais prevê apenas um limite para as chamadas Particulas Totais em Suspensão (PTS), que inclui desde poeira com até 100 micrômetros a material inalável com tamanho de até 10 micrômetros.

- Quanto mais fino for o material particulado, mais perigoso ele é para a saúde, então a primeira grande falha de nosso programa de qualidade do ar é não incluir o MP2,5 - diz Ferreira. - E mesmo para o MP10 nosso padrão de 50 microgramas por metro cúbico de ar, é mais do que o dobro do recomendado pela OMS, de 20 microgramas.

De acordo com Ferreira, esta defasagem observada nos limites para o material particulado se repete para o dióxido enxe e dos óxidos de nitrogênio. Além disso, o diretor-presidente do lema cobra a implantação de um sistema de monitoramento transparente da qualidade do ar nas grandes cidades brasileiras. No Rio, o Instituto Estadual do Ambiente (Inea), é responsável por este monitoramento. O órgão, no entanto, não soube precisar quantas estações fazem o levantamento na região metropolitana da cidade. Segundo informações disponíveis no site do Inea, seriam 26 no total, a grande maioria voltada apenas para análise de material particulado e só quatro, as únicas automáticas e localizadas em Jacarepaguá, no Centro, em Nova Iguaçu e em São Gonçalo, fariam medições dos outros poluentes. Além disso, o último relatório de qualidade do ar do estado na página do Inea data de 2009.

- Não adianta nada estabelecer padrões rigorosos se não há monitoramento, única maneira de observar se eles estão sendo atendidos. Há grandes capitais do país $\mathrm{cm}$ que milhões de pessoas estão vivendo sem nenhum monitoramento do ar que respiram - critica Ferreira, lembrando que é necessário ainda o investimento em politicas públicas. - É preciso integrar as políticas de transporte e mobilidade urbana às ambientais. 
A escolha do jornal O Globo foi relacionada ao importante papel desempenhado por ele na sociedade. Entre os jornais que circulam no Rio de Janeiro, é o que mais traz informaçóes sobre tecnologia, cultura, economia, política e atualidade, e o que engloba os acontecimentos ligados ao meio ambiente.

As matérias publicadas são as mais imparciais quando comparadas a outros jornais, que recorrem ao sensacionalismo estampado em primeira página, com o objetivo de atrair os leitores. O jornal O Globo tem 87 anos e é um dos mais influentes do Brasil.

Para analisar os resultados, tornou-se necessária a utilização de um questionário diagnóstico, que teve o objetivo de analisar o nível de conhecimento dos alunos sobre a temática proposta, ou seja, fazer um levantamento antes da introduçáo do texto, para que fosse possível a avaliaçáo dos resultados pós-atividade. Após a leitura e discussão do texto, foi aplicado um questionário final.

O questionário diagnóstico continha cinco questóes abertas sobre poluiçáo atmosférica. São elas: o que você entende por poluição e por poluição atmosférica? Quais poluentes da atmosfera você conhece? Quais doenças você acha que podem ser causadas pela poluição atmosférica? Você acha que é importante o controle da poluição atmosférica? Por quê? Em sua opinião, qual a importância do monitoramento da qualidade do ar? Essas questóes foram elaboradas com o objetivo de permitir que os alunos respondessem com as suas palavras, de forma livre. Desta forma, cria-se uma estratégia para averiguar os conhecimentos prévios do aluno e, ainda, deixar os alunos confiantes para responder as questôes, de forma que não se sentissem passando por uma avaliação, mas que pudessem responder com naturalidade, com maior desenvoltura.

$\mathrm{O}$ questionário final tinha o objetivo de verificar como os alunos conseguiam articular e problematizar as questôes relacionadas à poluição. Este questionário também foi composto por cinco questôes mais específicas, formuladas com base nas informaçóes contidas no texto e, também, em algumas informaçóes relacionadas ao primeiro questionário, que buscavam avaliar o grau de desenvoltura dos conhecimentos, de forma que pudesse ser realizada uma comparaçáo com as respostas do questionário prédiagnóstico.

As questôes foram: $\mathrm{O}$ que é poluição atmosférica? Quais são os principais poluentes atmosféricos? Quais são as doenças associadas à poluição atmosférica? Quais são os benefícios do controle da poluiçáo atmosférica para a sociedade? Por que é importante o monitoramento da qualidade do ar?

Neste estudo, utilizou-se o método do domínio cognitivo para analisar os questionários, considerando as seguintes características: conhecimento, compreensão, aplicação, análise, síntese e avaliação. Então, para avaliar o grau de compreensão e articulação de conceitos, ou seja, capacidades cognitivas diversas, pelos alunos, após a leitura do texto de divulgaçáo científica, as perguntas dos questionários foram numeradas e as respostas avaliadas individualmente, de acordo com as características e os objetivos cognitivos propostos por Bloom et al. (1973), procurando avaliar, nos alunos, capacidades cognitivas mais complexas em relação à temática proposta.

As características analisadas, neste trabalho, para a avaliação das respostas dos alunos foram: conhecimento (memorizaçáo de conceitos, terminologias e fatos específicos relacionados ao tema, tais como poluição atmosférica, gases poluentes, dióxido de carbono (CO2)); compreensão (além de entender o significado dos conceitos e terminologias, conseguindo explicar, por exemplo, as relaçôes entre os poluentes atmosféricos e as 
doenças relacionadas); aplicaçáo (aplica o aprendizado em novas situaçóes, discursando, por exemplo, sobre as consequências futuras da falta de controle na emissão de poluentes); análise (analisa elementos, conceitos, relaçóes e princípios de organização, de forma que transpareça seu conhecimento através do estabelecimento de comentários e críticas sobre a poluição atmosférica); síntese (reconhece as diferentes partes de um todo, ou seja, reconhece as causas da poluição, assim como as consequências para o meio ambiente e para a sociedade, mas também modos sustentáveis de moderar os impactos); avaliação (tem capacidade de avaliar todos os elementos e, além de explicar e reconhecer, julgar as informações)

Após esta etapa, desenvolveu-se uma balança de conhecimentos, analisando-se, em cada questáo, as relaçóes estabelecidas pelos alunos, chegando-se, então, a respostas que foram classificadas da seguinte forma: não respondeu, não conhece, conhece pouco, conhece parcialmente e conhece.

Os questionários pré e pós-diagnósticos passaram por este procedimento avaliativo e cada pergunta, de cada questionário, foi classificada individualmente; após essa classificação, os resultados dos aludidos questionários foram comparados e se tirou uma média dos resultados desta comparação. Através dessa comparaçáo, realizou-se uma nova avaliação, que apurou o aprimoramento das respostas, ou seja, se, depois da leitura do texto de divulgação científica e discussão do texto, o aluno absorveu as informaçôes esperadas, apresentando-as em sua resposta.

Nessa comparação entre os questionários diagnóstico e final, aplicou-se outra classificação, com o objetivo de se analisar o impacto do texto nas respostas. Essa nova classificação utilizou a comparação do desempenho dos alunos em suas respostas, de acordo com os domínios, nos dois questionários. Nessas condiçóes, o desempenho final de cada aluno foi classificado em: decrescido (aplicou melhor o conhecimento no questionário diagnóstico do que no final); igualitário (tanto nas respostas do questionário diagnóstico ou inicial quanto no diagnóstico final ele apresentou o mesmo grau de conhecimento); e acrescido (as respostas do questionário final apresentaram significativo grau de conhecimento e evolução em relação às respostas do questionário inicial).

\section{Resultados e discussáo}

A amostra da pesquisa foi constituída por 70 alunos, com idade entre 15 e 17 anos. Destes, 39\% eram do sexo masculino e 61\% do sexo feminino. Por se tratar de alunos do $3^{\circ}$ ano do Ensino Médio e o tema abordado ser comumente divulgado pelos meios de comunicaçáo, verificou-se que a maioria dos estudantes possuía algum conhecimento sobre o assunto, embora ainda não utilizando termos científicos ou explicaçôes mais elaboradas. Esses dados podem ser confirmados a partir do estudo de Rocha et al. (2013), que, ao analisarem a abordagem de temas ambientais em jornais e revistas de grande circulaçáo no Brasil, observaram que a temática poluição foi a mais recorrente.

$\mathrm{Na}$ primeira questão, pretendia-se avaliar o conhecimento sobre poluição e, especificamente, poluiçáo atmosférica. A resposta mais recorrente foi: "presença de substâncias prejudiciais ao meio ambiente", o que vem a demonstrar que, de forma de geral, os alunos possuíam conhecimentos básicos sobre o assunto. Comparando-se as respostas dos questionários pré e pós de um aluno, observa-se que, após a leitura do 
texto, o aluno apresentou uma explicaçáo mais elaborada e, sobretudo, utilizou uma terminologia mais próxima da científica para explicar o processo de poluição atmosférica.

Questionário pré-diagnóstico: "Presença de poluentes no meio e poluição atmosférica é a presença de poluentes na atmosfera".

Questionário pós-diagnóstico: "Poluição é quando meio ambiente (água, solo e ar) é contaminado por substâncias nocivas à saúde e a natureza. A poluição atmosférica é quando no ar existem substâncias nocivas (gases poluentes) em grande quantidade".

A segunda questáo tinha a proposta de avaliar os tipos de poluentes atmosféricos conhecidos pelos alunos. A grande maioria das respostas citou CFC (clorofluorcarbono), $\mathrm{CO}$ (monóxido de carbono) e $\mathrm{CO}_{2}$ (dióxido de carbono) Demonstrando mais uma vez um domínio básico do assunto, no entanto, observou-se que alguns alunos, após a leitura do texto, introduziram outros poluentes que náo haviam aparecido no questionário inicial:

Questionário pré-diagnóstico: "CO e $\mathrm{CO}_{2}$ ”.

Questionário pós-diagnóstico: “CO, $\mathrm{CO}_{3}, \mathrm{SO}_{2}$ e óxidos de nitrogênio”.

Quando questionados sobre as doenças que podem estar relacionadas à poluiçáo atmosférica, a maioria dos alunos se restringiu às doenças respiratórias. Já no questionário final, descrevem outras doenças:

Questionário pré-diagnóstico: "Doenças pulmonares".

Questionário pós-diagnóstico: "Doenças respiratórias, cardio-vasculares e até o câncer".

A quarta questão discutia a importância das medidas de controle da poluição atmosférica. Através da comparação entre as respostas antes e depois da leitura do texto, é possível observar que alguns alunos conseguiram relacionar a qualidade do ar com o bemestar dos seres vivos, como podemos ver a seguir:

Questionário pré-diagnóstico: "É importante verificar o ar que respiramos".

Questionário pós-diagnóstico: "O controle da poluição atmosférica é importante para reduzir a presença de partículas indesejadas no ar atmosférico e com isso preservar sua qualidade, garantido o bem-estar dos seres vivos".

Ao serem perguntados sobre a importância do monitoramento da qualidade do ar, esperava-se que apresentassem alguma relaçáo entre verificar a incidência de poluição de cada ponto e a tomada de medidas para melhorar a situaçáo quando necessária, porém, poucas respostas se enquadraram nesse perfil nos questionários pré-diagnóstico. Entretanto, tornou-se mais recorrente essa explicação no questionário final.

Questionário pré-diagnóstico: "Evitar a poluição, deixando assim um ar mais limpo, causando menos problemas ambientais e consequentemente menos doenças".

Questionário pós-diagnóstico: "Porque com o monitoramento, os poluentes prejudiciais à saúde podem ser detectados e as devidas providências poderáo tomadas. Podem até desenvolver projetos que façam isso".

Diante dos exemplos citados, observa-se um considerável enriquecimento nas respostas do questionário pós-diagnóstico, quando comparados com o pré. Após esta primeira avaliação, cada questáo foi devidamente classificada de acordo com os critérios 
destacados por Blomm et al. (1973). Em seguida, foi realizado um levantamento quantitativo dessas classificaçóes, que foram convertidas em resultados percentuais, conforme as Figuras 2 e 3.

\section{Figura 2: Contagem geral das classificaçóes das questôes do questionário diagnóstico}

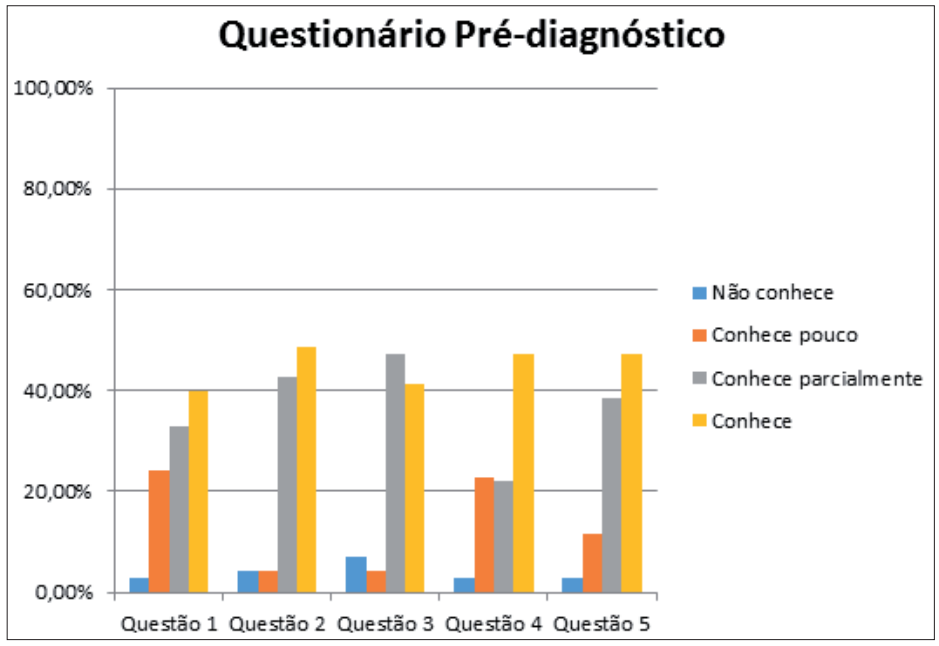

Fonte: A pesquisa

Figura 3: Contagem geral das classificaçóes das questóes do questionário final

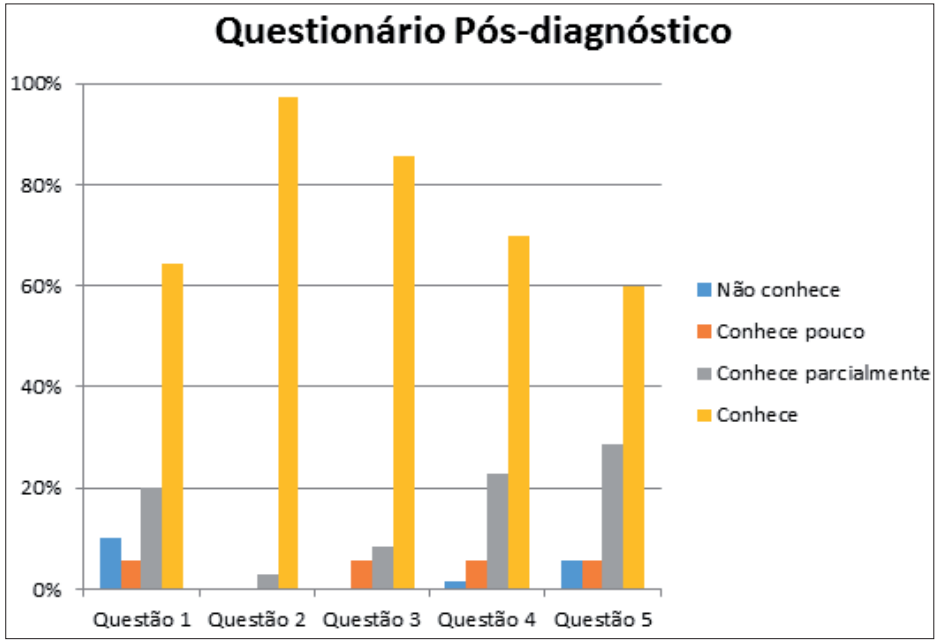

Fonte: A pesquisa

Se analisada cada questáo separadamente, observa-se um aumento expressivo da qualidade das repostas após a leitura e discussáo do texto. A questấo de número 1 apresentou acréscimo de $24,9 \%$ na classificação "conhece", nos questionários pósdiagnóstico; além disso, as classificaçôes "não conhece" e "conhece pouco" diminuíram de forma relevante.

Depois de realizada a contagem, observou-se que, em todas as turmas, os resultados obtidos foram positivos, corroborando o que Perticarrari et al. (2010) encontraram em estudo similar. Os autores afirmaram que o uso de um texto de divulgação adequadamente planejado, associado ao papel do professor, pode possibilitar que o aluno supere o nível de conhecimento de definiçóes e fatos, alcançando níveis mais complexos de temas relacionados ao meio ambiente. 
Muitos alunos conseguiram, além de memorizar e citar novas terminologias científicas relacionadas ao tema, articular os conceitos abordados no texto com seus conhecimentos prévios sobre o tema, fazendo relaçôes entre os conceitos da poluiçấo atmosférica e suas consequências, citando, inclusive, terminologias e informaçóes que estavam disponíveis no texto.

O resultado do balanço da avaliação geral dos questionários foi, então, satisfatório, como mostra a Figura 4, a seguir.

\section{Figura 4: Resultado geral da análise dos dois questionários}

\section{Balanço geral dos questionários}

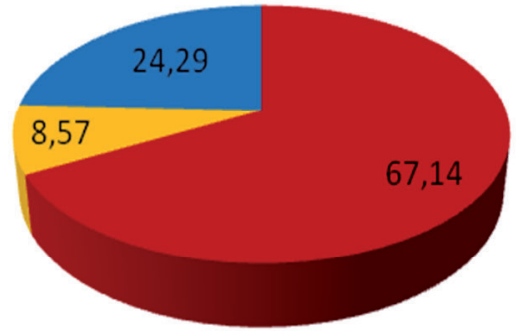

Acrescido

Decrescido

Igualitario

Fonte: A pesquisa.

O gráfico acima indica que aproximadamente $67 \%$ dos alunos apresentaram um acréscimo de conhecimento, demonstrando enriquecimento conceitual em suas respostas no questionário final, quando comparadas às respostas do questionário diagnóstico. Alguns pesquisadores relataram a importância da utilizaçáo dos textos de divulgaçáo científica para o ensino de novos conceitos no ambiente escolar, corroborando nossos resultados. Neste sentido, Ferreira e Queiroz (2011) evidenciaram o potencial da divulgação científica tanto no aprendizado de alunos do ensino médio, quanto do fundamental.

Rocha (2012) também avaliou a contribuição da divulgação científica como ferramenta de ensino. Em uma de suas pesquisas, investigou junto a professores que utilizam textos de divulgação científica em sala de aula e suas experiências com os alunos. Os resultados da análise realizada apontaram que o uso dos textos de divulgação científica é vantajoso, pois além de trazer para os alunos assuntos da atualidade, também atualizam pedagogicamente os professores.

Apesar disto, não são apenas os pontos positivos os enfatizados por pesquisadores. Nascimento (2005) ressaltou, em sua pesquisa, possíveis origens para o problema da utilização de textos de divulgaçáo científica em sala de aula e reforçou a ideia de que a absorção das informaçôes disponibilizadas em textos de divulgação cientifica estão diretamente relacionadas ao modo como o texto é produzido e como os professores inserem estes textos em sala de aula.

Realmente, a linguagem utilizada no texto é de extrema importância para o entendimento dos alunos, pois a linguagem científica é muito complexa e o autor do texto de divulgação científica, geralmente, o jornalista, precisa quebrar a complexidade da linguagem, transformando o complexo em simples, para que os alunos possam compreender e adquirir o conhecimento do texto. 
Além disso, também é importante o planejamento estratégico da atividade pedagógica, para incentivar o aluno à concentração para leitura, ao aprendizado e a expor os conhecimentos obtidos. Uma técnica utilizada para o sucesso do uso da divulgaçáo científica é propor um momento discussão após a leitura do texto. Esse é, para os alunos, um momento de contextualização sobre o seu entendimento a respeito do assunto, pois cada um entende de uma forma, e esse momento possibilita o compartilhamento das informações.

A partir do exposto, observa-se que pontos diversos e importantes têm sido estudados e analisados por pesquisadores sobre a divulgação científica, que, em geral, é reconhecida nestes trabalhos como importante ferramenta de veiculação de informaçóes científicas nas escolas.

\section{Conclusão}

O uso dos textos de divulgação científica, diferentemente dos textos encontrados em livros didáticos, que são utilizados para veicular informaçóes e conhecimentos aos alunos nas escolas, propicia a discussão de assuntos da atualidade científica, além de se constituírem em textos ricos em informaçóes científicas e com uma linguagem acessível.

Com base nos resultados obtidos, observou-se a grande importância do uso de textos de divulgação científica como recurso didático. Verificou-se, também, a relevância como prática pedagógica que apresentou significativa contribuição no aprofundamento de conceitos ambientais dos alunos participantes das oficinas. Sendo assim, as atividades apoiadas na leitura e discussão de textos de divulgaçáo cientifica foi eficiente, apresentando dados relevantes que merecerem ser divulgados, validando, por sua vez, nosso projeto de extensáo. Como desdobramentos deste estudo, podemos relacionar outras pesquisas que vêm sendo desenvolvidas por estudantes de graduação do CEFET/RJ, durante a iniciação científica.

Conclui-se, então, que se empregados de forma estruturada, os textos de divulgação podem auxiliar no processo de aquisição de conhecimentos científicos pelos estudantes. Este estudo reforça os resultados de outras análises realizadas sobre a utilizaçáo dos textos de divulgaçáo científica como ferramenta didática, ampliando o entendimento desta utilização e do impacto no aprendizado dos alunos.

Por fim, acredita-se que as propostas curriculares devem pensar o trabalho da temática ambiental abordando conceitos e terminologias, mas também contemplar atividades que incluam a leitura e discussão de uma variedade de textos, inclusive os de divulgação científica. Pois, desta forma, trarão para a sala de aula a oportunidade de desenvolver habilidades no aluno, contribuindo para um crescimento mais efetivo, não só quanto ao conhecer os fundamentos ambientais, mas também quanto ao conhecer e desenvolver sua capacidade de comunicação, de trabalho em grupo e de pensamento crítico. 


\section{Referências}

ABREU, L. N.; MASSI, L. E S. L. QUEIROZ. Textos de divulgação científica no ensino superior de química. In: ENCONTRO NACIONAL DE PESQUISA EM EDUCAÇÃO EM CIÊNCIAS, 6., 2007, Florianópolis. Atas... Florianópolis, 2007.

ALFERES, S.; AGUSTINI, C. A Escrita da Divulgação Científica. Horizonte Científico, v.2, n.1, p.1-2, 2008.

BELMONTE, R. Cidades em mutação. In: BOAS, S. V. (Org.). Formação e informação ambiental: jornalismo para iniciados e leigos. São Paulo, SP: Summus, 2004.

BERNARDES, E. S., VARÃO F. E.; SILVA, C. V. O aquecimento global na imprensa especializada e não-especializada: estudo comparativo das revistas pesquisa FAPESP, Scientific American Brasil, Veja e Carta Capital. In: XIII Encontro Latino Americano de Iniciação Científica e IX Encontro Latino Americano de Pós-Graduação, XIII, 2009, Universidade do Vale do Paraíba, Outubro, 2009.

BLOOM, B.S., KRATHWOHL, D. R., MASIA, B. B. Taxonomia de objetivos educacionais. Porto Alegre: Globo, 1973.

BRASIL, Ministério da Educação. Parâmetros Curriculares Nacionais Brasília: SEF/MEC, 1999.

BUENO, W. Comunicação científica e divulgação científica: aproximações e rupturas conceituais. Informação \& Informação, v. 15 (n. esp.), p. 1-12, 2010.

CHRISTOFOLETTI, R. Jornalismo, verdade e ética: divulgação científica e confusão informativa. 48-55. In: LOTH, M. (Org). Comunicando a ciência. Florianópolis: ABJC, 2001.

FERREIRA, L. N. A.; QUEIROZ, S. L. Autoria no ensino superior de química: análise de textos escritos por alunos de graduação. Ciência e Educação, v.17, n.3, p.541-558, 2011.

- Textos de Divulgação Científica no Ensino de Ciências: uma revisão. Alexandria Revista de Educação em Ciência e Tecnologia, v.5, n.1, p.3-31, 2012.

FREIRE, G. Educação Ambiental - princípios e práticas. São Paulo: Gaia, 2003.

GOLDBACH, T.; FRIEDRICH, M. P; STELING, L. P.; GANDARA, A.C.P. A utilização de artigos de divulgação científica no trabalho docente. In: I ENEBIO/ III EREBIO RJ/E. Anais... Rio de Janeiro: Sociedade Brasileira de Ensino de Biologia, 2005.

GOMES, M. Potencial das revistas de divulgação científica para o ensino dos temas Nutrição e Metabolismo Energético. 189f. 2008. Dissertação de Mestrado, (Mestrado em Comunicação para a Ciência) - Universidade Federal do Rio de Janeiro, Rio de Janeiro, 2008.

GOUVÊA, G. A divulgação científica para crianças - o caso da ciência hoje das crianças. $256 f$. 2000. Tese (Doutorado em Bioquímica Médica) - Universidade Federal do Rio de Janeiro, Rio de Janeiro, 2000.

KLEIMAN, A. Texto e leitor: aspectos cognitivos da leitura. 2. ed., Campinas - SP, 1989. 
MASSARANI, L. A divulgação científica no Rio de Janeiro: algumas reflexões sobre a década de 20. Rio de Janeiro: IBICT-ECO/UFRJ, 2008.

MENEGAT, T. M. C.; CLEMENT, L.; TERRAZZAN, E. A. Textos de divulgação científica em aulas de física: uma abordagem investigativa.In: ENCONTRO NACIONAL DE PESQUISA EM EDUCAÇÃO EM CIÊNCIAS, 6., 2007, Florianópolis Atas.... Florianópolis, 2007.

NASCIMENTO, T. G. O discurso da divulgação científica no livro didático de ciências: características, adaptações e funções de um texto sobre clonagem. Revista Brasileira de Pesquisa em Educação em Ciências, v.8, n.2, p.25-36, p.12-28, 2005.

PERTICARRARI, A.; TRIGO, F. R.; BARBIERI, M. R.; COVAS, T. D. O uso de textos de divulgação científica para o ensino de conceitos sobre Ecologia a estudantes da Educação Básica. Ciência \& Educação, v.16n.2, p.369386, 2010.

QUEIROZ, S. L.; FERREIRA. L. N. A.; IMASATO, H. Textos de divulgação científica no ensino superior de química: aplicação em uma disciplina de Química Estrutural. Educación Química, v.23, n.1, p.49-54, 2012.

RIGOTTI, G. Universidade e comunidade: uma aliança a ser construída. pp. 184-195. In: LOTH, M. (org). Comunicando a ciência. Anais...Florianópolis: ABJC, 2001.

ROCHA, M. B. Textos de divulgação científica na sala de aula: a visão do professor de ciências. Revista Augustus, Rio de Janeiro, v.14, n;.29), p. 24-34, 2010.

ROCHA, M. B. O potencial didático dos textos de divulgação científica segundo professores de ciências. $R$. B. E. C. T., v.5, n.2, p.47-68, 2012.

ROCHA, M. B., NICODEMO, J. O papel da divulgação científica na difusão de conhecimentos ambientais na Educação Básica. Ensino de Ciências e Tecnologia em Revista. v.3, n.2, p. 34-46, 2013.

ROCHA, M. B., MARQUES, R., QUARESMA, R. Avaliação da divulgação de questões ambientais em jornais e revistas como forma de Educação Ambiental. v.5, n10, P. 73-85, 2013.

SÁNCHEZ MORA, A. M. A divulgação da ciência como literatura. Rio de Janeiro: Editora UFRJ, 2003.

SILVA, H. C.; ALMEIDA, M. J. P. M. O deslocamento de aspectos do funcionamento do discurso pedagógico pela leitura de textos de divulgação científica em aulas de física. Revista Electrónica de Enseñanza de las Ciencias, V.4, p. $(30,155-179,2005$.

SOUSA, C. M., FERNANDES, A. M. Mídia e Meio Ambiente: limites e possibilidades. Departamento de Comunicação Social, Universidade de Taubaté, SP, 2008.

SULAIMAN, S. N. Educação ambiental, sustentabilidade e ciência: o papel da mídia na difusão de conhecimentos científicos. Ciência \& Educação, v.17, n.(3), p. 645-662, 2011.

TERRAZZAN, E. A. Analogias no ensino de ciências: resultados e perspectivas. In: SEMINÁRIO DE PESQUISA EM EDUCAÇÃO DA REGIÃO SUL, 3., 2000, Porto Alegre. Anais... Porto Alegre, 2000. 